\title{
Panorama da agricultura orgânica no Brasil
}

\author{
Ágatha Transfeld da Silva ${ }^{1}$ e Samantha Transfeld da Silva ${ }^{2}$
}

O artigo possui o propósito de reunir informações a respeito do panorama da agricultura orgânica no Brasil, enfocando questões relacionadas ao uso de agrotóxicos, situação econômica atual e dificuldades do mercado orgânico; segurança alimentar e nutricional dos alimentos produzidos de forma orgânica e convencional e sustentabilidade no que se refere ao cultivo convencional e orgânico de alimentos. Foram analisados os dados presentes nas bases de dados Pro Quest Research Library, Scielo, Science Direct, One File (Gale), Directory of Open Access Journals e Medline. Constata-se que o Brasil faz uso exacerbado de agrotóxicos quando comparado com outros países. A produção de alimentos é focada em mono cultivos dependentes de áreas extensas de plantio, assim como insumos químicos. A produção orgânica tem o potencial de proporcionar benefícios relacionados à ingestão alimentar, geração de trabalho e renda e conservação dos recursos naturais e da biodiversidade. Verifica-se a necessidade de estudos exploratórios investigando os efeitos dos agrotóxicos sobre a saúde e o meio-ambiente a longo prazo, assim como ao que se refere à composição nutricional dos alimentos orgânicos. Ações direcionadas ao fomento da atividade orgânica nas etapas envolvendo o cultivo, distribuição, comercialização e consumo ainda se fazem necessárias a fim de expandir e aprimorar este tipo de agricultura.

Palavras-chave: Agricultura Orgânica; Alimentos Orgânicos; Agrotóxicos; Produção de Alimentos.

\section{Panorama of Brazilian Organic Agriculture}

This article aimed at gathering information about the outlook of organic agriculture in Brazil, focusing on issues related to the use of pesticides, current economic situation, and difficulties of the organic market; food and nutrition security and sustainability concerning the conventional and organic cultivation. Data were obtained in the databases Pro Quest Research Library, Scielo, Science Direct, One File (Gale), Directory of Open Access Journals and Medline. Brazil makes heavy use of pesticides when compared to other countries. Food production is focused on monocultures, depending on extensive planting areas and chemical inputs. The organic production has the potential to provide benefits related to food intake, generation of employment and income, and conservation of natural resources and biodiversity. Exploratory studies on the effects of pesticides on health and environment in the long term are required, as well as regarding the nutritional composition of organic foods. Actions directed to the promotion of organic activity in the stages involving cultivation, distribution, marketing, and consumption are still necessary to expand and improve this kind of agriculture.

Keywords: Organic Agriculture; Organic Food; Pesticides; Food Production.

\footnotetext{
${ }^{1}$ Mestre em Alimentação e Nutrição. Universidade Federal do Paraná. Endereço para correspondência: Travessa Rafael Francisco Greca no 240, Água Verde, Curitiba, Paraná. CEP: 80620-150. Telefone: +55 (41) 99760-4266.E-mail: agatha.transfeld@gmail.com 


\section{INTRODUÇÃO}

O presente trabalho apresenta um panorama da agricultura orgânica no Brasil, destacando o uso de agrotóxicos e questão da segurança alimentar e nutricional.

O apelo crescente da população por uma alimentação saudável tem pressionado a indústria de alimentos a melhorar os padrões de qualidade de suas matérias-primas. De acordo com a Aliança de Centros de Pesquisa Orgânica - ORCA, a agricultura orgânica tem mostrado crescimento contínuo há mais de uma década e atualmente a procura por produtos orgânicos consegue ser superior à quantidade produzida ${ }^{[1]}$.

Do ponto de vista histórico, a agricultura orgânica teve início na década de 1920, com a busca por um sistema de produção que respeitasse a natureza e os consumidores. Porém, após a 2 a Guerra Mundial, iniciou-se a "Revolução Verde", lançada com o objetivo de utilizar as tecnologias desenvolvidas, sendo caracterizada por mono cultivos com intensivo uso de insumos químicos. $\mathrm{Na}$ década de 1970, os efeitos nocivos da prática agrícola convencional pelo uso intensivo de adubos químicos, foram evidenciados e questionados, impulsionando o desenvolvimento da agricultura orgânica [2].

A agricultura orgânica é um nicho de mercado que está atraindo cada vez mais interesse da população, estando articulada com outras correntes como a agricultura natural, biodinâmica, biológica, ecológica e permacultura. Estas correntes adotam princípios relacionados ao redesenho da produção agrícola, com a valorização das interações ecológicas e com a diminuição do uso de insumos químicos [3].

Campanhola e Valarini [3] argumentam que a agricultura orgânica é uma opção viável para o pequeno produtor, pois esta prática permite a diversificação de cultivos, sendo um meio de obtenção de renda durante o ano inteiro, como também fortalece o comércio local. $O$ fato de não utilizar insumos externos torna o custo efetivo de produção menor em comparação com a agricultura convencional.
O contexto global envolvendo escassez de recursos naturais devido ao uso extensivo da agricultura convencional, coloca desafios sem precedentes para a agricultura que podem ser solucionados por manejo orgânico e um renovado dimensionamento da produção e consumo de alimentos.

A agricultura orgânica, assim como de base agroecológica, oferece muitos benefícios sinérgicos para enfrentar os desafios biofísicos e socioeconômicos com o objetivo de reduzir a fome, a pobreza rural e a desigualdade, bem como, conservar os recursos naturais e a diversidade cultural [1].

No Decreto no 6.323, de 27/12/2007 [4] que regulamenta a Lei no 10.831 , de 23/12/2003, mais conhecida como Lei dos Orgânicos, tem-se como conceito de sistema orgânico de produção agropecuária todo aquele em que são adotadas técnicas que visam otimizar o uso de recursos naturais e socioeconômicos disponíveis, tendo como objetivo respeitar integralmente as características culturais das comunidades rurais, além de prezar pela sustentabilidade econômica e ecológica, como também, minimizar a dependência de energia nãorenovável, empregando sempre que possível, métodos culturais, biológicos e mecânicos, em oposição ao uso de materiais sintéticos, e ainda, eliminar o uso de organismos geneticamente modificados e radiações ionizantes.

Já o sistema de base agroecológica, é definido como aquele que busca desenvolver e otimizar a integração entre produção, utilização e conservação da biodiversidade e dos demais recursos naturais, equilíbrio ecológico, eficiência econômica e justiça social [5]. Este sistema, proveniente da interação entre diversas áreas do conhecimento, objetiva enfrentar as relações mais profundas da sustentabilidade, principalmente no que se refere ao modelo de desenvolvimento baseado na mercantilização e desiquilíbrio entre os parâmetros ecológicos, agronômicos, econômicos e socais. 
Dá-se destaque à elaboração e instituição da Política Nacional de Agroecologia e Produção Orgânica, por meio do Decreto no 7.794 de 20/08/2012 [5], com o objetivo de integrar, articular e adequar políticas, programas e ações que induzam a transição agroecológica e a produção orgânica e de base agroecológica, colaborando para o desenvolvimento sustentável e a qualidade de vida da população.

Observa-se mobilização por parte de instituições, sejam privadas ou governamentais, com o objetivo de incentivar o cultivo e consumo de alimentos orgânicos. No Brasil, é realizada anualmente a Semana dos Alimentos Orgânicos e foram desenvolvidos também Núcleos de Estudo em Agroecologia e Produção Orgânica e Bancos Comunitários de Sementes [6]. Existem programas que incentivam e facilitam a produção, aquisição e consumo de alimentos orgânicos, como: Programa de Aquisição de Alimentos (PAA), Programa Nacional de Alimentação Escolar (PNAE), Programa de Diversificação Econômica, dentre outros ${ }^{[7]}$.

Contudo, Assis [8] argumenta que as dificuldades para o mercado de produtos orgânicos são maiores e mais intensas comparando com grandes produtores patronais, principalmente no que se refere à diversificação do agroecossistema, visto que, no caso do cultivo orgânico trabalha-se próximo ao limite inferior da complexidade desejada. Além disso, nota-se uma menor interação com o mercado por parte destes produtores, refletindo assim na redução de adoção de tecnologias que visam ganhos de produtividade, como também menor facilidade de acesso a informações sobre estes produtos por parte dos consumidores.

O objetivo da presente revisão bibliográfica foi reunir informações que, de forma unificada, permitam a compreensão e reflexão a respeito do panorama da agricultura orgânica no Brasil, enfocando questões relacionadas a: a) uso/emprego de agrotóxicos; b) situação econômica atual e dificuldades do mercado orgânico; c) sustentabilidade e segurança alimentar e nutricional dos alimentos produzidos de forma orgânica e convencional.

\section{METODOLOGIA}

A metodologia adotada apresenta-se sob a forma de revisão bibliográfica dos dados presentes na literatura, sendo utilizados artigos na língua inglesa e portuguesa. Para a realização da pesquisa bibliográfica e compilação dos artigos foram empregados os seguintes descritores indexados pela Bireme: "agricultura orgânica", "alimentos orgânicos", "agrotóxicos", "produção de alimentos" e seus respectivos termos na língua inglesa.

Foram selecionados artigos presentes nas seguintes bases de dados: Pro Quest Research Library, Scielo, Science Direct, One File (Gale), Directory of Open Access Journals (DOAJ) e Medline.

Para seleção dos artigos, foram adotados como critérios de inclusão, os estudos publicados no período de 2001 a 2014, que abordavam como tema central a agricultura orgânica, assim como o uso/emprego de agrotóxicos em alimentos, produção de alimentos orgânicos e convencionais, segurança alimentar e nutricional dos alimentos produzidos de forma orgânica e convencional.

Foram excluídos os estudos que não abordavam de maneira aprofundada o tema central interligado aos tópicos de interesse deste artigo citados acima.

\section{Uso/emprego de agrotóxicos no Brasil}

O aumento na comercialização e utilização de agrotóxicos está relacionado a vários fatores, como o desejo pelo aumento da produção agrícola, redução de custos, desenvolvimento ascendente de monoculturas em grandes extensões, crescente resistência de pragas e fitopatógenos e expansão do plantio de soja transgênica resistente ao glifosato [?].

Conforme Decreto o 4.074 , de 4/01/2002 [10], os agrotóxicos e afins são definidos como agentes de processos físicos, químicos ou biológicos, que são destinados ao uso nos setores de produção, armazenamento e beneficiamento de produtos agrícolas, nas pastagens, na proteção de florestas, nativas ou plantadas, e de outros ecossistemas e de ambientes urbanos, hídricos e industriais, que têm como objetivo alterar a composição da flora ou da fauna, a fim de protegêelas contra a ação danosa de 
seres vivos considerados nocivos e de produtos empregados como desfolhantes, dessecantes, estimuladores e inibidores de crescimento.

Por meio dos dados compilados pela agência Nacional de Vigilância Sanitária - ANVISA e Universidade Federal do Paraná - UFPR [11] sobre "Mercado e Regulação de Agrotóxicos", tema abordado e discutido em seminário realizado pela Agência, sabe-se que o mercado mundial de agrotóxicos cresceu 93\% durante os anos de 2000 a 2010, sendo que, o mercado brasileiro, neste mesmo período de tempo apresentou um avanço de 190\%.

O Brasil se apresenta como o maior consumidor de agrotóxicos em escala mundial, seguido pelos Estados Unidos [12]. É possível verificar que o mercado global de agrotóxicos é caracterizado por oligopólio com alto grau de concentração, portanto, um número extremamente pequeno de empresas detêm o controle do mercado global do setor ${ }^{[11]}$.

Outra constatação refere-se à concentração de comercialização de categorias de produtos. Herbicidas, fungicidas e inseticidas, em ordem decrescente, são os gêneros de agrotóxicos mais utilizados no Brasil [11].

Dá-se destaque à soja transgênica, visto que, de forma global, a mesma é a cultura mais cultivada, e o glifosato o herbicida mais utilizado. Estados Unidos, Brasil e Argentina foram os principais produtores mundiais de soja em 2011, sendo que durante os anos de 2011 a 2012 a produção de soja transgênica nos Estados Unidos foi de aproximadamente $93-94 \%$ do total da produção, no Brasil este valor foi de $83 \%$ e na Argentina foi igual a $100 \%$ [13].

De acordo com o dossiê publicado pela Associação Brasileira de Saúde Pública - ABRASCO [14] dos 50 agrotóxicos mais utilizados nas lavouras do Brasil, 22 são proibidos na União Europeia, o que demonstra a necessidade evidente de regulação e fiscalização mais rigorosa no País. Conforme Pelaez, Silva e Araújo [12], as agências regulatórias brasileiras possuem limitações evidentes que interferem em sua atuação devido ao fato de serem subordinadas a ministérios e outros órgãos institucionais, não possuindo independência financeira e política para exercer de forma efetiva suas atividades.

Cox e Surgan [15] evidenciam em seu trabalho que as substâncias inertes presentes na formulação dos agrotóxicos podem aumentar a habilidade toxicológica da formulação dos pesticidas, incluindo o desenvolvimento de neurotoxicidade, genotoxicidade e disfunção hormonal. Eles possuem a capacidade de ampliar a exposição através do aumento da absorção dérmica, diminuindo a eficácia de roupas de proteção e aumentando a sua persistência no ambiente. Do mesmo modo, existe atuação direta das substâncias inertes sobre a fitotoxicidade das formulações de pesticidas, bem como, a toxicidade para peixes, anfíbios e micro-organismos.

Estudos demonstram que, além do contato direto com os agrotóxicos, estes também podem contaminar as pessoas através da ingestão de água e alimentos contaminados. A exposição crônica a pesticidas pode resultar em efeitos adversos sobre a pele, olhos, sistema nervoso, sistema cardiovascular, trato gastrointestinal, fígado, rins e sistema reprodutor e endócrino ${ }^{[16]}$.

Neste sentido, a pesquisa realizada por Araújo et al. [17], que objetivou analisar os aspectos fisiológicos, clínicos e laboratoriais da exposição múltipla a agrotóxicos em uma amostra de agricultores em Friburgo (Rio de Janeiro), revelou episódios leves a moderados de intoxicação aguda aos organofosforados descritos pelos agricultores ou observados durante o exame clínico. Foram também diagnosticados quadros de neuropatia tardia, quadros de síndrome neurocomportamental e distúrbios neuropsiquiátricos associados ao uso crônico de agrotóxicos.

Sena, Vargas e Oliveira ${ }^{[18]}$ relacionaram o uso de agrotóxicos com o grau de toxicidade, com a perda auditiva e com os índices de qualidade de vida, comprovando que os agricultores usuários de agrotóxicos apresentaram piores níveis de qualidade de vida quando comparados com aqueles que não utilizavam; o uso de agrotóxico e sua classe toxicológica interferiram de maneira incontestável direta no grau de perda auditiva. 
Cabe aqui questionar até que ponto o uso intensivo e crescente de agrotóxicos proporciona benefícios aos seres humanos no que se refere ao desenvolvimento da agricultura no País, visto que eles são os principais receptores destas substâncias. Adiciona-se à discussão, a permissão do uso de sementes transgênicas no Brasil que somente incentivou o maior consumo destes produtos, além de, também infringir diretamente o Direito Humano à Alimentação Adequada (DHAA).

O emprego de defensivos químicos possui potencial de ocasionar um desequilíbrio ecológico que se agrava devido a diminuição ou remoção de espécies, monocultivo e intoxicação humana e animal. Constata-se que critérios econômicos estão comandando tanto o modo de produção de alimentos como o consumo destes, aceitando-se conscientemente a poluição e as demais consequências provenientes do uso de defensivos agrícolas, fato que permite uma reflexão aprofundada e questionadora do papel do Estado e da população no sentido de promover e assegurar a Segurança Alimentar e Nutricional no Brasil de modo igualitário e satisfatório.

\section{Segurança Alimentar e Nutricional}

Conforme Lei no 11.346 de 15/09/2006 [19], a segurança alimentar e nutricional consiste na realização do direito de todos ao acesso regular e sem interrupção a alimentos de qualidade, em quantidade suficiente, sem prejudicar o acesso a outras necessidades essenciais, tendo como base práticas alimentares que promovam a saúde das pessoas, que respeitem a diversidade cultural e que sejam ambiental, cultural, econômica e socialmente sustentáveis.

Sendo assim, observa-se a grande dimensão de aspectos que acercam o tema, dando foco à integridade de nutrientes dos alimentos, como também, a ausência de substâncias que podem ocasionar danos à saúde daquele que os consumir.

Com este propósito, o Programa de Análise de Resíduos de Agrotóxicos em Alimentos (PARA), avalia continuamente os níveis de resíduos de agrotóxicos nos alimentos de origem vegetal que chegam à mesa do consumidor. A ANVISA coordena o programa em conjunto com as vigilâncias sanitárias dos estados e municípios participantes, onde são coletados alimentos do mercado varejista e os mesmos são analisados em laboratórios específicos ${ }^{[20] .}$

Em 2011 o Programa monitorou nove alimentos e em 2012 sete, os resultados obtidos mostraram que $36 \%$ e $29 \%$ de todas as amostras, analisadas nos anos em questão, respectivamente, apresentaram níveis de agrotóxicos acima do permitido ou não autorizados para a cultura, sendo estas irregularidades aparecendo de forma isolada ou simultânea. Em 2012, as culturas analisadas com maiores níveis de inconformidades na primeira fase do programa foram, em ordem decrescente: morango, pepino, abacaxi, cenoura, laranja, maçã e arroz; na segunda fase foram: abobrinha, alface, uva, tomate, feijão e fubá de milho [20]. Apesar da existência do Programa já ser considerada um avanço para o favorecimento da promoção da Segurança Alimentar e Nutricional no Brasil, percebe-se que este se caracteriza como uma medida que não atua diretamente onde se encontra $o$ problema, já que a avaliação dos resíduos de agrotóxicos é efetuada em um número limitado de alimentos e ocorre uma única vez por ano.

No Brasil, a maior parte da comercialização de produtos orgânicos ainda está concentrada em alimentos frescos, como frutas e vegetais, porém, produtos orgânicos embalados como café, arroz, molhos, condimentos e bebidas também apresentaram grande demanda, estimulando o desenvolvimento deste nicho de mercado [21].

Com isto, torna-se necessário o maior conhecimento a respeito dos produtos produzidos de maneira orgânica. Butler et al. [22] analisaram em seu trabalho, conduzido no período de dois anos, a concentração de ácidos graxos em leites comercializados no varejo na Inglaterra. Seus resultados mostram que as concentrações de ácidos graxos poliinsaturados ômega-3 e ômega-6 foram maiores em leites produzidos no sistema orgânico quando comparados aos leites produzidos de forma convencional.

Por meio do estudo de Vrcek et al. [23], foram analisadas amostras de farinha de trigo orgânica e convencional, comercializadas em supermercados na cidade de Zagreb, capital da Croácia. A farinha de 
trigo orgânica não obteve um teor de proteínas maior que o da farinha de trigo convencional, porém, sua digestibilidade se mostrou significativamente mais elevada, como também, seu teor de potássio, zinco e molibdênio, entretanto, apresentou níveis significativamente mais baixos de cálcio, manganês e ferro.

Campo et al. ${ }^{[24]}$ comparam a intensidade da cor, níveis de antocianina, ácido ascórbico e compostos fenólicos totais em morangos cultivados pelo sistema orgânico e convencional de produção, em Galícia na Espanha. As amostras de morangos orgânicos apresentaram teores significativamente superiores de antocianinas e ácido ascórbico, porém, os níveis de compostos fenólicos não diferiram em relação ao tipo de cultivo; os morangos orgânicos apresentaram características sensoriais, relacionadas a cor, mais atrativas do que os morangos convencionais.

Díaz-Gómez et al. [25] comentam em seu artigo sobre a contaminação preocupante do leite materno devido à ingestão de substâncias químicas tóxicas através dos alimentos, referindo a necessidade de elaboração de políticas públicas que objetivam a integridade da saúde da população e estimulam os esforços a favor da produção de alimentos orgânicos.

A questão que envolve a temática Segurança Alimentar e Nutricional dos alimentos orgânicos se refere à perspectiva do direito humano a alimentação adequada, considerando domínios relacionados com a qualidade, quantidade, acesso e disponibilidade dos alimentos. Apesar da discussão quanto a superioridade de concentrações de nutrientes dos alimentos produzidos organicamente ainda ser controvérsia, são irrefutáveis os benefícios que este tipo de produção pode proporcionar, de forma direta ou indireta, sobre a vida e saúde das pessoas [26].

Nota-se que a agricultura orgânica, ao contrário da agricultura convencional, pode atuar de maneira a favorecer a segurança alimentar e nutricional. A indicação de superioridade de nutrientes em produtos alimentícios cultivados de forma orgânica apresenta-se como um ponto benéfico adicional, visto que este tipo de agricultura mantém a fertilidade do solo, a sanidade geral de plantas, animais e do ser humano, promove a rotação de culturas e, ainda, não faz uso de compostos sintéticos, promovendo assim, o equilíbrio ecológico e a sobrevivência humana.

\section{Situação econômica atual e dificuldades do mercado orgânico}

O Brasil apresenta um alto grau de concentração no uso de terras, ou seja, poucos estabelecimentos agropecuários detêm um elevado percentual de extensão territorial [27].

Em relação à produção agrícola brasileira, as culturas que apresentaram maior expansão em 2009 foram a soja e a cana de açúcar, sendo que estas e, ainda, o milho possuem as maiores áreas de cultivo, ou seja, os monocultivos detentores de extensas áreas voltados principalmente para a exportação ${ }^{[28]}$.

Conforme dados referentes a 2010, os países com a maior área em produção orgânica são, respectivamente, Austrália, Argentina, Estados Unidos, Brasil, Espanha, China, Itália, Alemanha, Uruguai e França. Durante os anos de 2006 a 2010, nota-se que alguns países apresentaram maiores taxas de crescimento relativas às áreas destinadas a produção orgânica, sendo França, Polônia, Espanha, Bolívia, Turquia, República Checa, Portugal, Suécia, Alemanha e República da Macedônia [29].

De acordo com o Censo Agropecuário IBGE [27] de 2006, percebe-se que o cultivo de alimentos orgânicos era mais expressivo por parte dos pequenos e médios produtores. Ainda de acordo com o Censo, nota-se um valor expressivo de estabelecimentos que praticavam a agricultura orgânica, porém, sem possuírem a certificação de entidade credenciada.

Conforme Decreto no 6.323, de 27/12/2007 [4], o produtor orgânico deve integrar o Cadastro Nacional de Produtores Orgânicos, o que é possível somente se estiver certificado por um dos três mecanismos: a Certificação por Auditoria, onde a concessão do selo SisOrg é feita por uma certificadora pública ou privada credenciada no Ministério da Agricultura, Pecuária e Abastecimento; Sistema Participativo de Garantia caracterizando-se pela responsabilidade coletiva dos membros do sistema, que podem ser produtores, consumidores, 
técnicos e demais interessados, e também, obrigatoriamente, um organismo participativo de avaliação da conformidade credenciado junto ao Ministério da Agricultura, Pecuária e Abastecimento; e ainda, Controle Social na Venda Direta, a legislação brasileira abriu uma exceção na obrigatoriedade de certificação dos produtos orgânicos para a agricultura familiar, porém, exige-se o credenciamento numa organização de controle social cadastrado em órgão fiscalizador oficial. Com isso, os agricultores familiares passam a fazer parte do Cadastro Nacional de Produtores Orgânicos.

Conforme Willer e Kilcher [29], em 2010, os países que apresentaram maior mercado de alimentos orgânicos foram, em ordem decrescente: Estados Unidos, seguido pela Alemanha e França. No mesmo ano, o maior consumo per capita destes alimentos foi, respectivamente, na Suíça, Dinamarca e Luxemburgo.

Em relação aos valores dos produtos orgânicos no Brasil, Sousa et al. ${ }^{[30]}$ associam o valor agregado mais elevado à baixa procura que este mercado ainda possui, mostrando uma competitividade de mercado inferior aos produtos convencionais. Há também fatores relacionados à comercialização destes produtos, onde soma-se a margem de lucro de estabelecimentos comerciais, que muitas vezes é superfaturada. Além destes fatores, constata-se que a agricultura orgânica exige um maior envolvimento de mão de obra com possível consequência nos custos de produção.

Quanto à comercialização, uma alternativa em avanço no que se refere ao acréscimo de vendas é a exportação, sendo que mais de $70 \%$ da produção orgânica nacional destina-se principalmente para os Estados Unidos, Europa e Japão. Os alimentos mais exportados são açúcar; manteiga, gordura e óleos, café e cacau [31].

A agricultura orgânica possui inúmeras vantagens para a agricultura familiar, porém, o controle de qualidade exigido para estes produtos pode se tornar um entrave devido a insuficiência de assistência técnica adequada e acessível. Além disto, percebe-se que a falta de conhecimento dos produtores a respeito do processo de certificação interfere negativamente no desenvolvimento desta atividade. E ainda, verifica-se a necessidade do fortalecimento de associações e cooperativas de produtores, a fim de superar os obstáculos relacionados a produção e comercialização destes alimentos por parte de pequenos e médios produtores [32].

Analisando e associando os dados anteriores é possível verificar que o mercado brasileiro de produtos orgânicos ainda pode e deve ser desenvolvido de forma ampla, articulando todos os envolvidos, de modo a favorecer esta ascensão, visto que o fomento desta atividade tem a capacidade de contribuir para a formação e/ou inserção destes produtores em subsistemas agroindustriais, com decorrente consolidação deste tipo de agricultura.

Confirma-se a necessidade de complementar a assistência técnica destinada aos produtores orgânicos, tal como, a facilidade na certificação com incentivo de elaboração de novos produtos e da agroindústria de base familiar. Ademais, visa a ampliação do número de gêneros alimentícios nativos utilizados atualmente na alimentação brasileira, à mitigação dos problemas relacionados à dieta simplificada e ao fortalecimento da conservação e do manejo sustentável da biodiversidade.

\section{Sustentabilidade}

A industrialização gerou uma economia de cunho capitalista, onde a melhora cada vez mais evidente da eficiência das tecnologias desenvolvidas tem o objetivo de estimular o capitalismo em si [33]. Este desenvolvimento tecnológico associado a organizações de trabalho bem estruturadas têm a capacidade de aproximar as esferas de produção e consumo. Esta aproximação pode ser alcançada também através da valorização da produção local de alimentos, visto que, desta forma há o estímulo das relações econômicas locais, com busca por uma conexão saudável entre homem e ambiente e consequente apreciação das características culturais, sociais e ambientais [34].

A produção orgânica pode ser desenvolvida de maneira evidente por produtores patronais e, majoritariamente, pequenos e médios produtores [27]. A inserção destes em um sistema produtivo moderno e adaptado à realidade dos mercados atuais 
faz com que ocorra a geração de emprego e renda, e ainda desenvolvimento social e regional, contribuindo e assegurando a dignidade necessária, aos agricultores familiares e pequenos empresários rurais. As ações de estímulo para assegurar meios de sobrevivência digna devem integrar as políticas públicas, formando uma rede de suporte para a população brasileira, em especial à população rural [35].

Os produtos orgânicos tendem a ser mais seguros para o consumo por não apresentarem fertilizantes sintéticos solúveis e agrotóxicos, como também, pelo fato de não passarem pelo processo de modificação genética, apresentando assim, responsabilidade social e ambiental. São produzidos considerando o uso saudável e responsável do solo, da água, do ar e dos demais recursos naturais, favorecendo a redução da contaminação e do desperdício dos elementos, colaborando para o desenvolvimento sustentável. As propriedades orgânicas têm como objetivo gerar ecossistemas mais equilibrados, diversificando e integrando a produção de espécies vegetais e animais [36].

A diversidade que a flora nativa brasileira apresenta, sendo esta um patrimônio nacional, deve ser valorizada, e ainda, desenvolvida, através de inovações e melhoramentos proporcionados por pesquisas e estratégias tecnológicas que têm a finalidade de caracterizar a dinâmica da fauna e flora, dos microrganismos, do ambiente e sua interação social e econômica com as diversas comunidades, alcançando dessa forma, a preservação e a produção de alimentos saudáveis, oferecendo assim, maior qualidade de vida para o produtor e consumidor.

A valorização dos conhecimentos e tradições locais, assim como, representação política efetiva dos diversos segmentos da população, responsabilidade social e preservação do meio ambiente são dimensões que devem permear a visão da sociedade atual a fim de promover um desenvolvimento amplo e seguro tanto para a mesma, como também, para as populações futuras.

\section{CONCLUSÃO}

Ao analisar a situação atual no que se refere ao mercado de agrotóxicos e sua regulação, assim como a intensidade de uso dos mesmos no Brasil, nota-se que há necessidade de desenvolvimento de mais estudos e pesquisas que esclareçam a real dimensão dos efeitos, na saúde humana e no ambiente, exercidos pelas substâncias utilizadas nestes produtos.

Percebe-se a escassez de pesquisas, bem estruturadas metodologicamente, que explorem os efeitos sobre a saúde das pessoas que ingerem alimentos contendo agrotóxicos, como também, dos produtores rurais que utilizam estes produtos.

O cenário atual relacionado ao uso de agrotóxicos já é preocupante, do ponto de vista de saúde pública e ambiental, e deve-se levar em conta que as perspectivas são de agravamento dos problemas já citados, principalmente, devido ao crescente cultivo de monoculturas químicodependentes. Sendo assim, estratégias, ações e políticas que estimulem processos produtivos sustentáveis, fomento de pesquisas em torno do assunto e regulação efetiva e adequada do uso dos agrotóxicos são objetivos a serem traçados com ambição de alcançá-los.

É inegável a importância da biodiversidade para a garantia da segurança alimentar e nutricional, assim como as diversidades culturais que integram o Brasil permitem que se tenha ecossistemas produtivos e diversificados. As populações e suas características culturais formam um componente integral para a construção de ecossistemas agrícolas, e o desenvolvimento de seus sistemas e de suas organizações sociais é indispensável para o progresso sustentável da agricultura.

Poucos estudos sobre a composição nutricional de alimentos cultivados organicamente e convencionalmente estão disponíveis na literatura e apenas um pequeno número de alimentos produzidos por estes dois sistemas de cultivo foram analisados e comparados até o momento, fato que demonstra a necessidade de incentivo, investimento e preocupação por parte de instituições de pesquisa e do governo em relação a esta temática.

Embora alguns estudos comprovem os benefícios do plantio e consumo de alimentos orgânicos, verifica-se que pesquisas devem explorar ainda mais, com rigor metodológico, a questão que envolve os teores nutricionais destes alimentos, visto 
que, esta é uma temática de interesse para a saúde pública e possui âmbito mundial.

Desta forma conclui-se, através da presente revisão bibliográfica, a importância em desenvolver e fortalecer a agricultura orgânica no Brasil. Ações direcionadas ao fomento da atividade orgânica seja na etapa relacionada ao cultivo, distribuição, comercialização e consumo, ainda se fazem necessárias a fim de expandir e aprimorar este tipo de agricultura no País.

\section{REFERÊNCIAS}

[1] Food and Agriculture Organization of the United Nations. Organic Agriculture [internet]. Roma: Organic Research Centres Alliance (ORCA); 2014 [acesso em 23 mar 2015]. Disponível em: http://www.fao.org

[2] Ormond JG, Paula S, Filho PF, Rocha LT. Agricultura orgânica: quando o passado é futuro. BNDES Setorial. 2002;(15):3-34.

[3] Campanhola C, Valarini PJ. A agricultura orgânica e seu potencial para o pequeno produtor. Cad. Ciênc. Tecnol. 2001;18(3):69-101.

[4] Brasil. Decreto no 6.323, de 27 de dezembro de 2007. Regulamenta a Lei no 10.831, de 23 de dezembro de 2003, que dispõe sobre a agricultura orgânica, e dá outras providências. Diário Oficial da União. 28 dez 27.

[5] Brasil. Decreto no 7.794, de 20 de agosto de 2012. Institui a Política Nacional de Agroecologia e Produção Orgânica. Diário Oficial da União. 21 ago 2012.

[6] Brasil. Ministério da Agricultura, Pecuária e Abastecimento (Brasil). Orgânicos: Projetos [internet]. Brasília (DF); 2015 [acesso em 23 mar 2015]. Disponível em: http://www.agricultura.gov.br

[7] Brasil. Ministério do Desenvolvimento Agrário. Programas [internet]. Brasília (DF); 2015 [acesso em 23 mar 2015]. Disponível em: http://www.mda.gov.br

[8] Assis RL. Desenvolvimento rural sustentável no Brasil: perspectivas a partir da integração de ações públicas e privadas com base na agroecologia. Econ. Apl. 2006;10(1):75-89.

[9] Domingues MR, Bernardi MR, Ono EYS, Ono MA. Agrotóxicos: Risco à Saúde do Trabalhador Rural. Semina Ciênc. Biol. Saúde. 2004;25(1):45-54.
[10] Brasil. Decreto no 4.074, de 4 de janeiro de 2002. Regulamenta a Lei no 7.802, de 11 de julho de 1989, que dispõe sobre a pesquisa, a experimentação, a produção, a embalagem e rotulagem, o transporte, o armazenamento, a comercialização, a propaganda comercial, a utilização, a importação, a exportação, o destino final dos resíduos e embalagens, o registro, a classificação, o controle, a inspeção e a fiscalização de agrotóxicos, seus componentes e afins, e dá outras providências. Diário Oficial da União. 04 jan 2002.

[11] Brasil. Agência Nacional de Vigilância Sanitária ANVISA. Universidade Federal do Paraná. Mercado e regulação de agrotóxicos. Seminário Mercado e Regulação de Agrotóxicos [internet]. Brasília (DF); 2012 [acesso em 23 mar 2015]. Disponível em: http://portal.anvisa.gov.br

[12] Pelaez V, Silva LR, Araújo EB. Regulation of pesticides: a comparative analysis. Science Public Policy [Internet]. 2013 [acesso em 2015 mar 2];40(5):644-656. Disponível em: http://spp.oxfordjournals.org/content/40/5/644

[13] Bohn T, Cuhra M, Traavik T, Sanden M, Fagan J, Primicerio R. Compositional differences in soybeans on the market: Glyphosate accumulates in Roundup Ready GM soybeans. Food Chem. 2014;(153):207-215.

[14] Carneiro F, Rigotto R, Giraldo L, Pignati W, Rizzolo A, Alexandre VP, Faria NMX, Friedrich K, Mello MSC. Dossiê ABRASCO - Um alerta sobre os impactos dos agrotóxicos na saúde. Rio de Janeiro: Associação Brasileira de Saúde Coletiva - ABRASCO; 2012.

[15] Cox C, Surgan M. Unidentified Inert Ingredients in Pesticides: Implications for Human and Environmental Health. Environ. Health Perspect. 2006;114(12):1803-1806.

[16] World Health Organization. Preventing disease through healthy environments [internet]. 2010 [acesso em 2015 mar 23]. Disponível em: http://www.who.int

[17] Araújo AJ, Lima JS, Moreira JC, Jacob SC, Soares MO, Monteiro MCM, Amaral AM, Kubota A, Meyer A, Cosenza CAN, Neves C, Markowitz S. Exposição múltipla a agrotóxicos e efeitos à saúde: estudo transversal em amostra de 102 trabalhadores rurais, Nova Friburgo, RJ. Ciênc. Saúde Coletiva. 2007;12(1):115-130.

[18] Sena TR, Vargas MM, Oliveira CCC. Saúde auditiva e qualidade de vida em trabalhadores expostos a agrotóxicos. Ciênc. Saúde Coletiva. 2013;18(6):1753-1761.

[19] Brasil. Lei no 11.346, de 15 de setembro de 2006. Cria o Sistema Nacional de Segurança Alimentar e Nutricional SISAN com vistas em assegurar o direito humano à alimentação adequada e dá outras providências. Diário Oficial da União. 15 set 2006. 
[20] Brasil. Agência Nacional de Vigilância Sanitária. Programa de análise de resíduos de agrotóxicos em alimentos (PARA) - Relatório de atividades de 2011 e 2012 [internet]. Brasília (DF); 2013 [acesso em 23 mar 2015]. Disponível em: http://portal.anvisa.gov.br

[21] Brasil. Instituto de Promoção do Desenvolvimento. Pesquisa - O mercado brasileiro de produtos orgânicos [internet]. Curitiba; 2011 [acesso em 23 mar 2015]. Disponível em: http://www.ipd.org.br

[22] Butler G, Stergiadis S, Seal C, Eyre M, Leifert C. Fat composition of organic and conventional retail milk in northeast England. Am. Dairy Sci. Assoc. 2011;94(1):24-36.

[23] Vrcek IV, Cepo DV, Rasic D, Peraica M, Zuntar I, Bojic M, Mendas G, Medic-Saric M. A comparison of the nutritional value and food safety of organically and conventionally produced wheat flours. Food Chem. 2014;143:522-529.

[24] Campo JC, Damaceno MN, Rodríguez MAR, Odériz MLV. Color, anthocyanin pigment, ascorbic acid and total phenolic compound determination in organic versus conventional strawberries. J. Food. Compost. Anal. 2012;28(01):23-30.

[25] Díaz-Gómes NM, Ares S, Hernández-Aguilar MT, Ortega-García JA, Paricio-Talayero JM, Landa-Rivera J; Comité de Lactancia Materna de la Asociación Española de Pediatría. Contaminantes químicos y lactancia materna: tomando posiciones. An. Pedriatr. (Barc). 2013;79(6):391.e1391.e5.

[26] Borguini RG, Torres EAF. Alimentos Orgânicos: Qualidade Nutritiva e Segurança do Alimento. Segur. Aliment. Nutr.2006;13(2):64-75.

[27] Brasil. Instituto Brasileiro de Geografia e Estatística IBGE. Censo Agropecuário: Brasil, Grandes Regiões e Unidades da Federação. Rio de Janeiro: IBGE; 2006.
[28] Brasil. Instituto Brasileiro de Geografia e Estatística IBGE. Produção Agrícola Municipal: culturas temporárias e permanentes. Rio de Janeiro: IBGE; 2009.

[29] Willer H, Kilcher L; Research Institute of Organic Agriculture; International Federation of Organic Agriculture Movements. The World of Organic Agriculture - Statistics and Emerging Trends 2012 [internet]. 2012 [acesso em 23 mar 2015]. Disponível em: http://www.fibl.org

[30] Sousa AA, Azevedo E, Lima EE, Silva APF. Alimentos orgânicos e saúde humana: estudo sobre as controvérsias. Rev. Panam. Salud Publica. 2012;31(6):513-517.

[31] Terrazzan P, Valarini PJ. Situação do mercado de produtos orgânicos e as formas de comercialização no Brasil. Informações Econômicas. 2009;39(11):27-40.

[32] Vriesman AK, Okuyama KK, Rocha CH, Neto PHW. Assistência Técnica e Extensão Rural para a Certificação de Produtos Orgânicos da Agricultura Familiar. Revista Conexão. 2012;8(1):138-149.

[33] Bauman Z. Vida para consumo: a transformação das pessoas em mercadorias. Rio de Janeiro: Jorge Zahar; 2007.

[34] Belik W, Siliprandi E. Ministério do Desenvolvimento Agrário; Secretaria da Agricultura Familiar. Instituto Via Pública. Projeto Nutre SP: Análise da inclusão da agricultura familiar na alimentação escolar no estado de São Paulo; 2012.

[35] Brasil. Ministério da Agricultura, Pecuária e Abastecimento. Produção Integrada no Brasil, agropecuária sustentável e alimentos seguros. Brasília (DF): Ministério da Agricultura, Pecuária e Abastecimento; 2008.

[36] Smolinski R, Guerreiro E, Raiher AP. Análise do mercado de produtos orgânicos: estudo de caso de feira em Ponta Grossa, PR. Desenvolvimento e Meio Ambiente. 2011;23:167-182. 